\title{
A VUELTAS CON LA FRASEOLOGÍA HISTÓRICA IBERORROMÁNICA (LOCUCIONES ADVERBIALES Y PREPOSITIVAS EN ESPAÑOL $Y$ PORTUGUÉS)*
}

\author{
NEW APPROACHES TO THE STUDY OF \\ IBEROROMANCE HISTORICAL PHRASEOLOGY (ADVERBIAL AND \\ PREPOSITIONAL PHRASES IN SPANISH AND PORTUGUESE)
}

David Porcel Bueno

Universidad de Granada daporbue@ugr.es

\begin{abstract}
RESUMEN
La fraseología histórica tiene como principal objetivo estudiar el origen y el proceso de formación de las unidades fraseológicas, determinando su funcionamiento gramatical y el contenido semántico que han adquirido en cada etapa de su evolución diacrónica. En este artículo hemos realizado un repaso por los principales trabajos que se han ocupado del estudio histórico de las locuciones del ámbito iberorrománico, marco de referencia en el que se integra un análisis descriptivo sobre algunas locuciones adverbiales y prepositivas que son comunes al castellano y al portugués medievales.
\end{abstract}

Palabras clave: histórica, locuciones adverbiales, locuciones propositivas, lingüistica contrastiva, castellano medieval, portugués medieval.

\begin{abstract}
The main objective of historical phraseology is to study the origin and development of phraseological units, determining their grammatical functioning and the semantic value that they have acquired at each stage of their diachronic evolution. In this paper, we have carried out a contrastive analysis on some adverbial and prepositional phrases that are common to Medieval Spanish and Portuguese.
\end{abstract}

Keywords: Historial Phraseology, adverbial phrases, prepositional phrases, Medieval Spanish, Medieval Portuguese, linguistic variation.

\footnotetext{
* Este trabajo se inscribe en el proyecto "Historia e historiografía de la lengua castellana en su diacronía contrastiva" (HISLECDIAC) con referencia FFI2017-83688-P, financiado por la Agencia Estatal de Investigación (AEI) y el Fondo Europeo de Desarrollo Regional (FEDER) y gestionado por la Universidad de Valencia a través del Departamento de Filología Española.
} 


\section{A MODO DE INTRODUCCIÓN. EL ESTUDIO HISTÓRICO DE LAS LOCUCIONES ADVERBIALES Y PREPOSITIVAS DESDE UNA PERSPECTIVA IBERORROMÁNICA}

Por lo que respecta al estudio histórico de las locuciones, Lapesa (1981) fue uno de los primeros estudiosos de la diacronía lingüística que llamó la atención sobre estos esquemas complejos, los cuales estaban llamadas a ocupar un lugar destacado en el entonces llamado Diccionario bistórico de la lengua española. Hasta ese momento, solo algún estudio parcial se había ocupado de estos esquemas prepositivos (Skelton, 1971). Poco a poco fueron surgiendo nuevos trabajos que trataban algunos aspectos históricos de estas estructuras fijas (Pons y Ruiz, 2001ㅜㄹ ; Martín Zorraquino, 2002), aunque no será hasta Echenique Elizondo (2003) cuando la fraseología histórica del español adquiera un estatuto propio, a medio camino entre el estudio del léxico y la sintaxis.

El principal interés de esta nueva perspectiva analítica era estudiar el proceso diacrónico a través del cual las locuciones del español habían ido adquiriendo (gradualmente) las características semánticas y funcionales que hoy día tienen en el repertorio fraseológico actual. En este sentido, no sólo se puso de manifiesto que el estudio diacrónico de estos esquemas era fundamental para la historia del español (Echenique Elizondo, 2010), sino que además sus posibilidades de análisis desde el punto de vista de la lingüística contrastiva eran enormes (Echenique Elizondo, 2011). Sobre este último aspecto volveremos más adelante.

Desde un punto de vista no estrictamente fraseológico, algunas locuciones adverbiales han sido objeto de estudio en Rodríguez Molina (2014) y Ortiz Ciscomani (2014): en el primer caso se establece una clasificación semántica de los adverbios y las locuciones de manera (sustentada, en buena medida, en argumentos morfológicos), y

\footnotetext{
${ }^{1}$ En el estudio que Pons y Ruiz (2001, p. 351) llevan a cabo sobre los orígenes del conector de todas maneras se ponen de manifiesto algunas de las limitaciones que venían afectando al estudio histórico de estos esquemas prepositivos: "En este proceso quedan preguntas sin resolver en distintos ámbitos: desde el punto de vista formal, resulta recurrente la fijación preferente con ciertos tipos de preposiciones (en el caso que nos ocupa, en y de), que no parece haber sido explicada hasta ahora; desde el punto de vista funcional, queda abierta la cuestión de por qué las funciones de determinante y de modificador de un adjetivo, desarrolladas durante un período relativamente dilatado de tiempo, dejan de documentarse a finales del barroco y han desaparecido hoy en día. Desde el punto de vista pragmático, habría que explicar el porqué de la sustitución de en todas maneras por de todas maneras. Estas y otras preguntas quedan fuera del presente trabajo".
} 
en el segundo se estudian las locuciones adverbiales de significado modal que poseen como característica común la copresencia de la preposición a y una base léxica con la terminación - as (a ciegas). También se ha estudiado el proceso diacrónico a través del cual ciertos adjetivos se acaban convirtiendo en locuciones adverbiales (Ortiz Ciscomani, 2017), una evolución que según Ocampo (2006a, 2006b) es evidente en el caso de adjetivos como claro y bueno (debido a un proceso de discursivización).

En tanto que palabras gramaticales, Espinosa Elorza (2010) ha estudiado los esquemas de/por cierto, a tuerto o de mancomún, y ha puesto de manifiesto que locuciones como a lo mejor o de seguro experimentaron evoluciones semántico-discursivas importantes en el siglo XIX (Espinosa Elorza, 2012). Por su parte, Octavio de Toledo (2016) en su estudio sobre la evolución de los relacionantes locativos en español, se ha referido a aquellos elementos que permiten ubicar la posición en el espacio de una entidad con respecto a la otra (a lo largo, de lo alto de, en lo hondo, a par de, al parejo, en el derecho, al igual, etc.).

Muchas locuciones prepositivas y adverbiales han sido objeto de estudio por parte de la tradición lexicográfica, y no solo desde una perspectiva sincrónica. Especial interés tiene la nómina de locuciones adverbiales que Satorre Grau (2008) extracta de la lexicografía hispanolatina de los Siglos de Oro, así como las locuciones prepositivas y adverbiales que Quilis Merín (2008) documenta en la lexicografía española, desde Nebrija a Franciosini. Por su parte, en Álvarez Vives (2010) se estudian las locuciones que aparecen en las obras lexicográficas de Nicolas Mez de Braidenbach, así como en los diccionarios de Vicente Salvá y Esteban Pichardo (Álvarez Vives 2013). Respecto a la presencia de locuciones en la tradición gramaticográfica española siguen siendo fundamentales los trabajos de Gómez Asencio (2003, 2008a, 2008b).

Si hay un campo especialmente abonado en el estudio histórico de la fraseología ese es el de las locuciones prepositivas, sobre todo las que vieron la luz en el castellano medieval. Tomando como base un conjunto de obras jurídicas e historiográficas, Codita (2016) estudió los esquemas binarios $(\mathrm{P}+\mathrm{N})$ y complejos $(\mathrm{P}+\mathrm{N}+\mathrm{P})$ más representativos en el castellano de los siglos XIII al XV. Por su parte, Porcel Bueno (2016b, 2017a, 2017b) ha estudiado una treintena de obras pertenecientes a la literatura 
sapiencial de los siglos XIII, XIV y XV, evidenciando las implicaciones discursivas que los esquemas preposicionales complejos $(\mathrm{P}+\mathrm{X}+\mathrm{P})$ tuvieron en el desarrollo de un género fundamental para la historia de la fraseología (tanto en su concepción estrecha como ancha). También se han estudiado de manera pormenorizada las locuciones que aparecen en la obra del Marqués de Santillana, un autor que como ha demostrado Vicente Llavata (2011) representa en sí mismo un verdadero microcosmos fraseológico. Para la relación entre la métrica medieval y la fraseología, son fundamentales los trabajos de Pla Colomer (2016, 2017).

En el ámbito del portugués el estudio histórico de la fraseología parece no ha experimentado un desarrollo tan acentuado, si bien es cierto que en posible encontrar algunas referencias en obras de carácter más general.

Desde el punto de vista lexicográfico, Costa $(2009,2012)$ ha estudiado las locuciones espaciales y temporales, clarificando el origen latino de alguna de ellas. Por su parte, Cezario (2016) ha estudiado las locuciones adverbiales que se utilizan con más frecuencia en las cartas de jesuitas escritas en los siglos XVI y XVII, así como las locuciones adverbiales documentadas en cartas oficiales brasileñas del siglo XIX (Cezario, 2014), trabajo este último muy próximo al que años antes realizara Paulino Machado (2013). Cezario (2005) pone de manifiesto que ciertas locuciones documentadas en textos religiosos aparecen siempre en una posición pre-verbal, y estudia el caso concreto de às vezes y de la locución prepositiva, à luz de. En muchos de estos trabajos de carácter histórico no se hace una clara distinción entre los sintagmas libres y las unidades fraseológicas. Esto no sucede en Ricós Vidal (2011), donde se estudian promenorizadamente las locuciones adverbiales que aparecen en los diccionarios trilingües portugueses del siglo XVII. Álvarez de la Granja (2005) nos proporciona igualmente una nutrida nómina de locuciones adverbiales del gallego medieval (de acarreo, a baldon, a caron, de carreto, etc.) ${ }^{2}$; muchas de ellas coincidentes con formas portuguesas.

\footnotetext{
${ }^{2}$ Respecto a la fraseología histórica del catalán, Griera (1931, p. 97-98) ya ofrecía una lista con algunas de las locuciones más habituales del catalán medieval: al devall, a derredor, de dret, en gir, al present, a estonades, de veres, al tort $i$ al dret, de debó, a la biorxa, a betzeps, a benvista, per be, en cerca, en cert, de cor, a despit, etc. También Moll (1952, p. 204) al referirse a los adverbios de cantidad más frecuentes en la historia del
} 


\section{LAS LOCUCIONES ADVERBIALES Y PREPOSITIVAS DEL CASTELLANO Y DEL PORTUGUÉS MEDIEVALES. APROXIMACIONES A UN EST'UDIO CONTRASTTIVO}

Como ya apuntábamos más arriba, desde las primeras propuestas teóricometodológicas de la fraseología histórica se adoptó una perspectiva analítica eminentemente contrastiva, a través de la cual fuese posible estudiar tanto el modelo subyacente latino, como el proceso de formación (en buena medida común) de las locuciones adverbiales y prepositivas de ámbito iberorrománico (Echenique, 2003).

Los estudios que sitúan al español como primum comparationis y al portugués como secundum han sido enormemente favorecidos dentro de esta perspectiva contrastiva. Ricós Vidal (2006) estudió algunas locuciones adverbiales $(\mathrm{P}+\mathrm{X})$ que eran comunes a estas dos lenguas en el siglo XVI. También llevó a cabo un estudiado pormenorizado de los esquemas formados por $a+$ adjetivo $(\mathrm{P}+\mathrm{A})$, llegando a la conclusión de que se trata de uno de los esquemas más productivos en la creación de locuciones adverbiales (Ricós Vidal, 2008, p. 1036). Más recientemente, Ricós Vidal (2016) ha estudiado también las locuciones prepositivas complejas $(\mathrm{P}+\mathrm{X}+\mathrm{P})$ que son comunes al gallego y al portugués medievales, mientras que en García Valle y Ricós Vidal (2017) se analiza la expresión de la causa a través de las locuciones prepositivas documentadas en las crónicas alfonsíes y en sus traducciones al gallego y al portugués. Retomando esta última cuestión de las traducciones, García Valle (2018) ha realizado un estudio contrastivo de las locuciones prepositivas de finalidad documentadas en castellano y en portugués medievales, mientras que Pla Colomer y Vicente Llavata (2019) han abordado el estudio contrastivo (castellano-portugués) de las obras medievales de materia troyana.

Con todo, e independientemente de la lengua a la que nos refiramos, todo estudioso de la fraseología histórico-contrastiva debe afrontar dos escollos metodológicos: a) en

catalán, señalaba que las locuciones adverbiales se solían formar con la preposición $a$ más un elemento nominal, como a balquena, a la baldor, a l'uf, a cabassos, a cacarrells, etc. Más recientemente, algunos investigadores han analizado pormenorizadamente algunas locuciones adverbiales muy productivas en la historia del catalán antiguo, como es el caso de de part (Bruguera, 1981), en funció de (Vilaró, 1987), y otros esquemas prepositivos complejos $(\mathrm{P}+\mathrm{X}+\mathrm{P})$ (Casanova, 1984). En Perera $(1986,1987)$ se estudian también algunos $\mathrm{P}+\mathrm{X}$ característicos de catalán del siglo $\mathrm{XV}$. 
estadios de la lengua pretéritos no siempre es fácil distinguir fehacientemente la adscripción adverbial o prepositiva de una determinada unidad fraseológica, y b) a menudo es difícil entrever con claridad la filiación semántica que se establece entre unidades fraseológicas pertenecientes a una misma categoría locucional, máxime cuando se trata de variantes de una misma forma.

A este respecto, Codita (2016, pp. 35-41) ha llamado la atención sobre la confluencia entre ciertas locuciones prepositivas y algunos adverbios o locuciones adverbiales, tanto a nivel sintáctico, como desde el punto de vista de su valor semántico. En el caso del francés, Fagard (2009, p. 15) se ha referido también a esta misma interrelación, ampliándola al caso de las preposiciones simples:

Les locutions prépositionnelles formées sur une base nominale n'ont pas d'équivalent formel mais présentent une synonymie partielle avec certaines prepositions, ce qui n’a rien d'étonnant; cette synonymie semble cependant très limitée, du moins dans les cas retenus ici (por l'amor de, en lieu de / por). Les locutions prépositionnelles formées sur un adverbe ou un NLI, elles, présentent un sens distinct des prépositions simples 'correspondantes', même lorsqu'il y a proximité formelle évidente (e.g. devant et au devant de), avec par ailleurs une polysémie moindre. ${ }^{3}$

Solo el análisis del funcionamiento sintáctico y de la articulación discursiva que manifiestan estas estructuras fijas dentro de un contexto lingüístico amplio, nos permitirá determinar su valor semántico (y en algunos casos, idiomático) de las locuciones implicadas. A más de esto, y teniendo en cuenta que nos enfrentamos a unidades fraseológicas que de documentan en textos medievales, es importante diferenciar entre variantes de tipo fraseológico y variantes de tipo textual (Porcel Bueno, 2018).

\footnotetext{
${ }^{3}$ Esta frontera difusa entre las locuciones adverbiales y las prepositivas es perceptible también en el español y el portugués actuales. Ya en Cunha y Cintra (1984, pp. 540-542) se estableció una clasificación semántica de estos esquemas fijos y se introdujo una interesante observación sobre el papel que juega la preposición simple: "Quando uma preposição vem antes do advérbio, não muda a natureza deste; forma com ele uma locução adverbial: de dentro, por detrás, etc. Se, ao contrário, a preposição vem depois de un advérbio ou de uma locução adverbial, o grupo inteiro transforma-se numa locução prepositiva: dentro de, por detrás de, etc.". En la misma línea, Bechara (2001, p. 301) se refiere a las locuciones prepositivas formadas por un adverbio (o locución adverbial) seguida de las preposiciones de, a o com y ofrece una extensa lista de aquellas formas que son más usadas.
} 
Asociada al fenómeno de la variación (o como consecuencia de esta) nos encontramos también ante la cuestión de la sinonimia entre locuciones. Desde una perspectiva amplia, ambos fenómenos representarían las dos caras de un mismo impulso que tiende a evitar la repetición en beneficio del enriquecimiento estilístico (Ullmann 1987, pp. 170-171). La consideración de la sinonimia como una variación más restrictiva, basada en el reconocimiento de los sinónimos como variantes en alternancia libre, es muy útil para el proceder diacrónico. Como ha señalado RodríguezPiñero, el resultado de esta equivalencia significativa es que las unidades fraseológicas sometidas a examen devienen variantes libres en el plano de la expresión de un mismo contenido semántico, de ahí que tanto las variantes estructurales (gráficas, morfológicas o léxicas) como las locuciones semánticamente equivalentes (pero que no responden a ningún tipo de variación estructural) constituyan verdaderos ejemplos de sinonimia (2012, pp. 232-233). He aquí algunos ejemplos del castellano del siglo XIII acompañados de sus variantes con artículo modificador del sustantivo: ${ }^{4}$

(1) E dixo non te llegues al Rey quando a muchos enbargos en so regno. Quando entran los omnes en la mar en sazon que esta queda $\&$ non les faze tormenta ninguna sera marauilla si puede escapar. \& pues o que fara quando entraren en sazon de muchos uientos \& en sazon de muchas tormentas. (Anónimo, Poridat de poridades, s. XIII)

(2) Mas porque uieron que estauan en tiempo de guerras \& de conquistas \& auien mester Rey uuiado. dexaronse daquello \& alçaron por Rey a Gisalaygo hermano del Rey Alarigo que fue. maguer que era de ganancia. (Alfonso X, Estoria de Espanna, s. XIII)

(3) Sean vuestras bocas en loar a Dios en ora de coita e de folgura, e en pobreza e en riqueza. (Anónimo, Bocados de oro, s. XIII)

(4) Escrivió Sócrates su carta para un rey de los que eran a la sazon de socrates. (Anónimo, Libro de los buenos proverbios, s. XIII)

(5) E entre lo sabidores de mal es tenido por muy sabidor al tienpo de agora el que con enganno diciendo palabras mentirosas quiere engañar los omnes. (Anónimo, Castigos del rey don Sancho $I V$, s. XIII)

(6) El que vieres que se te da por amigo a la ora de cuyta e de la priesa e non cata por la su ganaçia ni por la su pérdida en tal de te saluar. (Anónimo, Castigos del rey don Sancho IV, s. XIII)

La segunda modalidad de la sinonimia apuntada por Rodríguez-Piñero (2012, p. 234) tiene lugar cuando las locuciones comparten un mismo significado y basan su diferencia, no en el contraste de parte de sus elementos, sino en toda su expresión

\footnotetext{
4 Real Academia Española: Banco de datos (CORDE) [en línea]. Corpus diacrónico del español. $<$ http://www.rae.es> [21/01/2020]
} 
formal (partiendo del examen de los contenidos expresados por los fraseologismos, con independencia de la forma lingǘstica que adopten). Desde un punto de vista histórico, y tratándose de locuciones prepositivas inmersas en un proceso de fijación potencial (formal y semántica), esta modalidad de la sinonimia es más difícil de entrever, ya que su configuración es bastante rígida y normalmente es preciso que compartan un patrón estructural semejante. ${ }^{5}$

Desde los primeros estudios sistemáticos sobre las unidades fraseológicas del castellano medieval se puso de manifiesto que las distintas variantes de una forma locucional casi siempre operaban sobre la base de cuatro patrones de cambio: la inserción del artículo modificador del sustantivo, la mudanza de la preposición inicial (y en menor medida, de la preposición final), la variación morfemática del núcleo de la locución y la variación léxica (Vicente Llavata, 2011). Lógicamente, a cada uno de estos cambios le corresponden unos índices de frecuencia que varían según las épocas y los géneros discursivos.

La variación fraseológica afectada por la mudanza de la preposición inicial presenta algunas peculiaridades que la hacen más proclive a desarrollar ambigüedad e indeterminación semánticas (no obstante, como hemos visto en los ejemplos antes mencionados, algunas variantes fraseológicas tienen el mismo significado idiomático). Por su parte, la variación morfemática del núcleo no suele tener consecuencias semánticas, si bien es cierto que el porcentaje de casos documentados es más reducido que en el caso anterior. Quizá el aspecto más controvertido tiene que ver con la conmutación de varias voces que actúan como núcleo de una misma locución, ya que esta modalidad de cambio suele acarrear alteraciones en su significado ${ }^{6}$.

\footnotetext{
${ }^{5}$ La reflexión sincrónica en torno a las relaciones sinonímicas que se establecen en el seno del sistema locucional tiene un amplio recorrido (cf. Zuloaga Ospina, 1980; Corpas Pastor, 1996; García-Page, 1998, 2008; Álvarez de la Granja, 1999, 2008; Penadés Martínez, 2006; Olímpio de Oliveira, 2007; RodríguezPiñero, 2011, 2012). En los últimos años ha habido un cambio en la consideración paradigmática de la sinonimia interfraseológica, ya que hay quienes consideran la sinonimia como la variación formal de un mismo contenido semántico dentro de una misma lengua funcional (Penadés 2006; Rodríguez-Piñero 2011, 2012), perspectiva que contrasta vivamente con las consideraciones más clásicas respecto a la diferenciación entre la variación de las expresiones fijas y su diferenciación respecto a la sinonimia (Zuloaga Ospina, 1980; Corpas Pastor, 1996; García-Page, 1998, 2008).

${ }^{6}$ En Porcel (2016a, 235-250) creímos oportuno restringir este tipo de variación fraseológica a aquellas locuciones que por su filiación etimológica pertenecían a una misma familia léxica, siendo los distintos procesos de derivación locucional los encargados de articular las distintas variantes.
} 
Con un proceder analítico marcadamente descriptivo, el principal objetivo de este trabajo no es otro que llamar la atención sobre ciertas locuciones prepositivas del castellano y del portugués medievales que experimentan una mudanza en la preposición inicial durante su proceso de conformación. Para ello nos serviremos de la información textual que nos transmiten tanto el Corpus Diacrónico del Español (CORDE) ${ }^{7}$ como el Corpus Informatizado do Português Medieval (CIPM). ${ }^{8}$

Un caso paradigmático de variación fraseológica lo constituye el grupo de locuciones formadas sobre la base de la palabra fin: a fin de/ a fim de, en fin de/em fin de. Esta nómina se incrementa sustancialmente si tenemos en cuenta las variantes que presentan artículo modificador del sustantivo: al fin de/ ao fim de, a la fin de/ na fim de, en la fin de/ na fim de, en el fin de/ no fim de, etc. (algunas de estas formas con artículo presentan una cronología más antigua que la de las variantes sin artículo):

(7) Este dezir fizo e ordenó Juan Alfonso de Baena, escrivano del Rey, como en manera de respuesta que le dava al dicho Alfonso Álvarez, como en manera de respuesta a este otro su dezir e so entençión e a fin de travar con él reqüesta. (Alfonso de Villasandino, Cancionero de Baena, s. XV)

(8) E porquamto este vellume he p(ri)mçipallmemte ordenado a fim de se comtarem os feitos \& obras daqueste comde, seg(umd)o mamdado dell rrey dom Afomsso, queremos fazer começo no azo que aquelle comde ouve pera ficar naquella çidade. (Gomes Eanes de Zurara, Crónica do Conde D. Pedro de Meneses, s. XV)

(9) Esta fallan en la laguna que a nombre belfiz; \& della toma este nombre. \& esta laguna es en fin de la tierra a que llaman Karuquia. \& tienes con la tierra que dizen india. (Alfonso x, Lapidario, s. XIII)

(10) E em fim de todo ueeo aquel caualeyro ao monte Oliuete, hu Jhesu Christo sobiu aos ceeos, e disse asy: Meu Senhor Jhesu Christo, nõ sey hu uaa mais depos ty. (Anónimo, Orto do Esposo, s. XV)

Como apuntábamos más arriba, la variación de la preposición inicial que suele llevar aparejada una mudanza del significado, haciendo que los distintos pares locucionales adquieran un valor modal, temporal, locativo o instrumental. Así lo vemos también en el caso de a cabo de/a cabo de, en cabo de/ em cabo de, de cabo de/de cabo de. Respecto a esta última forma, cabe decir que estaría más cerca de la categoría adverbial ("[comenzar] de cabo) que de la prepositiva, pese a presentar una estructura compleja. Esto evidencia

7 Real Academia Española: Banco de datos (CORDE) [en línea]. Corpus diacrónico del español. http://www.rae.es $[02 / 02 / 2020]$

${ }^{8}$ Banco de datos (CIPM) [en línea]. Corpus Informatizado do Português Medieval https://cipm.fcsh.unl.pt $[03 / 02 / 2020]$ 
una vez más que nos encontramos en un periodo de fluctuación en el que los distintos esquemas prepositivos todavía no han alcanzado un grado de fijeza consolidado y las distintas variantes conviven y se alternan en el seno de una norma lingüística que es anterior al proceso de codificación que tendrá lugar a partir de los siglos XV y XVI (en el caso español y portugués respectivamente).

En los siguientes ejemplos vemos como la adición del artículo modificador del sustantivo puede suponer también un cambio en el significado (las formas en cabo de/em cabo de y al cabo de/ ao cabo de estarían semánticamente muy próximas):

(11) E desque este Josué murió, a cabo de tienpo demandaron los fijos de Isrrahel a dios que les diese rey terrenal. (Anónimo, Castigos del rey don Sancho IV, s. XIII)

(12) Estonces los Romanos. teniendolo por mal. \& non lo podiendo sofrir. enuiaron con su hueste contra ellos a furio Camillo que era estonces so dictador \& ueno a los de uenecia al cabo de los terminos de su cibdad. \& de los dessos de uenecia. (Alfonso x, General Estoria, s. XIII)

(13) Por veer o gran miragre que a Virgen demostrara de como aquel meninno de morte ressucitara, que a cabo de seis dias jazendo morto chorara por prazer da Groriosa santa e dereitureira. (Alfonso X, Cantigas de Santa Maria, s. XIII)

(14) E por esta rrazom se veo ao cabo do Momtijo que he em Ribatejo duas legoas da çidade, omde ja tiinha huũ batell prestes em que passasse. (Fernão Lopes, Crónica de Dom João I, s. $\mathrm{XV})$

(15) Juntamiento de XII philosophos de los griegos en una claustra de los rreyes y en cabo de la claustra las siellas de los rreyes muertos, y los rreyes muertos en ellas, y enbiertos con paños preçiados y con oro. (Anónimo, Libro de buenos proverbios, s. XIII)

(16) El Rei Daragom que estava em cabo de seu Reino, quamdo isto soube, ficou espamtado, e mandou a Proemça, omde amdava o comde Dom Hemrrique e seus irmaãos e os outros fidallgosde Castella desterrados do reino fazemdo guerra. (Fernão Lopes, Crónica de Dom Pedro I, s. XV)

(17) Et entonçe començaron commo de cabo de lidiar todos de buelta \& tanto cresçio la sobejadunbre delos moros que mataron aquellos trezientos caualleros que venjeron en ayuda alos infantes. (Anónimo, Crónica de 1344, s. XV)

(18) E o Cide começou come de cabo de fazer guerra aos de Vallença, a maiis cruel que elle pode, de guisa que fez sobyr o pam tres tanto do que vallia em começo da cerca. (Anónimo, Crónica Geral de Espanba, s. Xv)

Dentro de este grupo de locuciones con valor locativo, algunas variantes con artículo son predominantes en toda la historia del español y del portugués. Es el caso del portugués ao longo de y de las formas castellanas a lo largo de y al longo de. Esta última forma (¿acaso un portuguesismo?) tuvo escaso éxito y no sobrevivió más allá del siglo XVI. 
(19) E, quando lhe o cavalocorrer ao longo do monte onde se o porco quer lançar, embarga o porco, que se non lança atan aginha no monte como se lançaria se lhe assi non corresse e, pollo alongar que se o porco alonga polla armada, o alaão tem melhor espaço pera o poder melhor filhar. (Anónimo, Livro de Montaria, s. XIV)

(20) E le den todo su axuar, e todo lo suyo lo metan allí con ella; e le pongan allí las cosas que menester oviere para su mantenimiento. E aluenguen la nave tanto dentro, a lo largo de la mar, fasta que non vean la tierra. E que alçen la vela, e que la dexen ansí sola en la mar. (Gutierre Díaz de Games, El Victorial, s. XV)

(21) Y fallé todo tan baxo el fondo, que no pude entrar ni navegar a ella, y vide que siguiendo el camino del Sudueste era muy gran rodeo, y por esto determiné de me bolver por el camino que yo avía traído del Nornordeste de la parte del Güeste, y rodear esta isla para aí. Y el viento me fue tan escasso, que yo no nunca pude aver la tierra al longo de la costa, salvo en la noche. (Anónimo, Diario del primer viaje de Colón, s. XV)

Esto mismo sucede con algunas locuciones prepositivas con valor modal, como a la manera de / à maneria de. En muchos casos parece que es precisamente el artículo modificador del sustantivo el responsable de inclinar la balanza hacia la fijación fraseológica, alejando dichos esquemas de la sintaxis libre.

(22) Et a estos cabdiellos deste poder que fazien de nueuo; llamaron tribunos. \& al so poder tribunado. \& dieronles este poder a la manera de los otros tribunos que fizieran de cada companna. (Alfonso X, Estoria de Espanna, s. XIII)

(23) Pois que faz aquel cavalgar que cavalgam? He mais à maneira dos que am-de andar à guerra que oque fazem os que justam. Se quiserdes bem veredes que o encontrar das justas non faz os homes ser tam avisados en encontrar como o que anda ao monte. (Anónimo, Livro de Montaria, s. XIV)

Pese a todo, la variación más común dentro de esta modalidad semántica suele ser la que afecta a la preposición inicial. Así lo vemos en las variantes a semejança de / a semelhamça de y en semejança de / em semelhança de:

(24) Si alguna cosa tira la fe, todos los onbres a estado pristino serán tornados, conuiene a saber, a poca cosa o a semajança de los animales brutos. (Anónimo, Secreto de los secretos, s. XIII) (25) Hos dõees do bautismo sõ sete a semelhamça dos sete dõees do spiritu sancto. O primeyro he o sal que poeem en na boca ao que ha de rreçeber o bautismo. (Clemente Sánchez de Vercial, Sacramental, s. XV)

(26) La imagen de la Tierra figurávanla en semejança de muger coronada, mas otra guisa grand era, e grandes miembros los otros otrossí, e desavida e espantosa, con una catadura sañuda, e las vestiduras e la corona pintado. (Alfonso X, General Estoria, s. XIII)

(27) E foi ao muimento e quis erguer a campãã, e viu sair ũũ fumo tam negro como pez, depois ũa chama, depois ũa figura em semelhança de homem, a mais fea e a mais estranha cousa que nunca homem viu. (Anónimo, Demanda do Santo Graal, s. XV) ${ }^{9}$

${ }_{9}$ Ambas lenguas documentan también en el periodo medieval las variantes con artículo a la semejanza de / à semelhança de. 
Respecto a las formas encabezadas por la preposición $a$, se documentan variantes que presentan una variación morfemática del núcleo: a semelhante de / a semejante de. Su frecuencia en español fue notablemente menor que en portugués, ya desde época medieval:

(28) E ante que morresse a Virgen, fora feita / a semellante dela por destroyr a seita / dos judeus e do demo, que sempre nos espreita / por fazer que caiamos en err' e en folya. (Alfonso X, Cantigas de Santa María, s. XIII)

(29) E aqueste término a do el albugíneo se ayunta con el vítreo e los tres humores que son en la media sustançia del ojo, el vno es vítreo, por quanto sea a semejante del vedrío desleído. (Anónimo, Traducción de la Cirugía Mayor de Lanfranco, s. Xv)

Para terminar, baste recordar que este rico despliegue de variantes fraseológicas se da con la misma intensidad en el caso de las locuciones adverbiales del castellano y del portugués medievales. En la entrada que el Diccionario de la lengua española consagra a la palabra cierto se recogen cuatro locuciones adverbiales formadas sobre la base de este adjetivo, al cierto, de cierto, por cierto y en cierto, de las cuales solo esta última aparece marcada como en desuso. Como se desprende de los siguientes ejemplos, las variantes de cierto, en cierto y por cierto ${ }^{10}$ tienen una larga trayectoria en la historia de fraseología española:

(30) Non quiso so padre e dixo: "Selo, mio fijo, selo". Que aun exira de él pueblos e acrecerá de cierto so ermano el menor. (Almerich, La fazienda de Ultra Mar, s. XII)

(31) De lo que yo façì él me á descubierto, / numca me fabló ombre ninguno tan en cierto, / mas, si me lo defiende poblado nin yermo, / tenerme ýa por nada, más que vn seco ensierto. (Anónimo, Libro de Apolonio, s. XIII)

(32) Por alimpiarse de sus pecados, / non calçaban çapatos. / Noche e día a Dios servién, / sabet por cierto que non durmién. (Anónimo, Vida de Santa María Egipciaca, s. XIII)

${ }^{10} \mathrm{La}$ forma por cierto, que en castellano medieval podía equivaler al adverbio 'ciertamente', suele entrar en concurrencia con las locuciones verbales haber/tenerpor cierto, tal y como se desprende de los siguientes ejemplos: a) "fija fue d'un Futifaris, que era obispo de Eliopoleos, que es la cibdad del sol o seyé ell ídolo en qe dava el sol sus respuestas a los pueblos de los gentiles que tenién ellos por ciertas" (Alfonso X, General Estoria. Primera parte, si. XIII); b) "Guardad que estas palabras son verdaderas creed las y haued las por ciertas" (Gonzalo García de Santamaría, Traducción de la Corónica de Aragón de fray Gauberto Fabricio de Vagad, s. XV). 
Estas formas convivieron con otras variantes más efímeras que no han llegado al repertorio fraseológico actual. Es el caso de a cierto y a la cierta, esta última documentada en un texto hispano-latino de finales del siglo VIII: ${ }^{11}$

(33) Priusquam ante que ad rectum alarierta coniugium ueniat (Anónimo, Glosas Silenses, s. X) (34) Bolvién los estrumentos a buelta con las aves, / modulavan a çierto las cuerdas e los claves, / alçando e premiendo fazién cantos süaves, / tales que por Orfeo de formar serién graves. (Anónimo, Libro de Alexandre, s. XIII)

Por su parte, la forma al cierto, que se alterna con ciertamente en muchos contextos, es posterior, ya que solo empieza a documentarse ampliamente a partir del siglo XVI:

(35) Los nombres de los otros dos hermanos no he podido averiguar al cierto mas de que ambos fueron hombres de armas, y el menor dellos casó en Castroxeriz. (Esteban de Garibay, Memorias de Garibay, s. XVI)

Del lado portugués las cosas no son muy diferentes. El Dicionário Houaiss da língua portuguesa, recoge las locuciones adverbiales ao certo, por certo, más las variantes en femenino, à certa, na certa, pela certa. Los textos medievales en cambio nos ofrecen otras variantes que quedaron varadas en alguna etapa del proceso de fraseologización, y no han sobrevivido en el portugués normativo actual. Es el caso de a certas, a certa, em certo y de certo, equivalentes a las más recientes 'com certeza', 'certamente', 'decerto': 12

(36) E u singravan pelo mar, atal foi ssa ventura / que sse levou mui gran tormenta, e a noit' escura / se fez, que ren non lles valia siso nen cordura, / e todos cuidaron morrer, de certo o sabiades. (Alfonso X, Cantigas de Santa María, s. XIII)

(37) Quem ouve aquestas mhas paravras, e as faz, semelharey a el o barom sages, que eivigou a ssa casa sobre a pedra, veerom os rrios, soprarom os veentos, e impetarom naquela casa, e non caeou, a certas era fundada sobre a pedra. (Anónimo, Regra de São Bento, s. XIV)

(38) E porque Nos auemos dito que em Jtalhya ajnda trazem al molheres mais grande estado posto que seja verdade. nom som ellas de tan grandes rraaos como aquy a çerta som. (Anónimo, O livro das tres vertudes, s. XV)

(39) Se esperas molher, nõ sabes em certo se a tomaras ou qual ou quejanda a tomaras. (Anónimo, Orto do esposo, s. XIV)

11 Pese al extraño paréntesis de más de ocho siglos, esta forma encuentra un eco a finales del siglo XVI: "Que un ingenio grosero / ofrecer la miseria / de tan pequeña suma, / a quien con tantas veras dio a la pluma / ocasión, y materia, / hace como el que lleva al mar hinchado, / agua, arena, o pescado, / o a Febo le da lumbre / siendo el que al mundo la que tiene ha dado, / o a la cierta le añade pesadumbre (Vicente Espinel, Diversas rimas, s. XVI).

$12 \mathrm{Al}$ igual que en el caso castellano, la forma por certo suele confluir con la locución verbal haver por certo: "E porem me praz trazer taaes cousas em duvyda se as magnifestamente nom vir, e naquellas, ainda que as por certas aja, fallar pouco a gente estrangeira, e com razoes bem reguardadas" (Dom Duarte, Leal Conselheiro, s. XV) 
(40) Saibas por certo que nemhũa cousa fez o glorioso deus uazia nas naturezas. (Anónimo, Segredos dos segredos, s. XV)

\section{CONCLUSIONES}

Las unidades fraseológicas que hemos analizado en este estudio contrastivo evidencian que muchas locuciones prepositivas y adverbiales afectadas por algún tipo de variación fraseológica presentan comunidad de significado, tanto en castellano como en portugués; otras muestran todo lo contrario, constatando que hay cambios formales que pueden redundar en una disparidad semántica entre variantes que podríamos considerar casi homónimas. Así pues, se pone de manifiesto que la mudanza de la preposición inicial es la modalidad variacional más común, seguida de la adición del artículo modificador y de la variación morfemática del núcleo. Hay además locuciones prepositivas y adverbiales que por su propia naturaleza tienen un carácter marcadamente polisémico, pese a manifestar un alto grado de fijeza.

Respecto a las relaciones sinonímicas que pudieran establecerse entre ciertas locuciones prepositivas o adverbiales, cabe recordar que, muy pocas unidades simples o complejas son completamente sinónimas en el sentido de que puedan ser intercambiables en cualquier contexto lingüístico sin la más mínima alteración del contenido semántico. Esto es aún más evidente cuando se trata de unidades fraseológicas que se documentan en textos medievales.

Por último, se ha puesto de manifiesto que estas locuciones comunes al castellano y al portugués medievales, con todo su aparato de variantes, son especialmente productivas a partir del siglo XIII, cuando se inaugura un periodo de fluctuación en el que distintas formas conviven dentro de una misma norma lingüística. Este fenómeno de la variación locucional tan característico de las lenguas iberorrománicas irá desapareciendo gradualmente, sobre todo a partir del momento en el que tienen lugar los distintos procesos de codificación, a través de los cuales el español y el portugués irán adquiriendo respectivamente el estatuto de lengua estándar. 


\section{BIBLIOGRAFÍA}

Álvarez de la Granja, M. (1999). Variación e sinonimia nas unidades fraseolóxicas. Caracterización xeral e proposta de tratamento lexicográfico, Cadernos de Lingua, 19, pp. 43-64.

Álvarez de la Granja, M. (2008). As variantes funcionais das locucións verbais, en C. Mellado Blanco (Ed.), Colocaciones y fraseología en los diccionarios, Frankfurt am Main: Peter Lang, pp. 33-51.

Álvarez Vives, V. (2010). Apuntes de fraseología histórica: las locuciones adverbiales en el "Diccionario muy copioso de la lengua española y alemana[...]" de Nicolas Mez de Braidenbach (1670), en M. ${ }^{a}$ T. Encinas Manterola (Ed.), Ars longa: diez años de AJIHLE, vol. 2, Buenos Aires: Voces del Sur, pp. 515-530.

Álvarez Vives, V. (2013). Estudio fraseológico contrastivo de las locuciones adverbiales en los diccionarios de Vicente Salvá y de Esteban Pichardo: hacia una fraseología histórica del español en la lexicografía del siglo XIX, Valencia: Universitat de València.

Bechara, E. (2001 [1999]). Moderna Gramática Portuguesa. Edição Revista e Ampliada, Rio de Janeiro: Lucerna.

Bruguera, J. (1981). La locució prepositiva de part, el present històric i el perfect perifràstic en la Crònica de Jaume I, en P. Bohigas (Ed.), Estudis de Llengua i Literatura Catalanes, III, Miscel-lània, vol. 1, Barcelona: Abadia de Montserrat, pp. 27-42.

Casanova, E. (1984). Sobre la construcció prepositiva N+P1+C+P2+T en català antic, en A. Badia i Margarit et al. (Eds.), Estudis de llengua i literatura catalanes, Miscel-lània, vol. 9, Barcelona: Abadia de Montserrat, pp. 43-63.

Cezario, M. M., Ilogti de Sá, É. C. y J. O. Costa Nunes (2005). Ordenação de adverbiais temporais ou aspectuais, Transformar, Revista do CenPE/Fundação São José, 3, pp. 214-227.

Cezario, M. M. y D. Castanheira (2014). Locuções adverbiais de tempo em cartas oficiais do século XIX: motivações para a ordenação, Revista Soletras, 28, pp. 41-59, https://doi.org/10.12957/soletras.2014.13356.

Cezario, M. M. (2016). A ordenaçao de locuções adverbiais de tempo em cartas jesuíticas dos séculos XVI e XVII, Signótica, 28, pp. 557-580. https://doi.org/10.5216/sig.v28i2.35599.

Codita, V. (2016). La conformación y el uso de las locuciones prepositivas en castellano medieval. Madrid: Iberoamericana Vervuert. https://doi.org/10.31819/9783954875771

Corpus diacrónico del español. REAL ACADEmia Española: Banco de datos (CORDE) [en línea] http://www.rae.es [02/02/2020]

Corpus Informatizado do Português Medieval. Banco de datos (CIPM) [en línea]. Corpus Informatizado do Português Medieval https://cipm.fcsh.unl.pt [03/02/2020]

Costa, S. B .B. (2009). Fontes lexicais de adverbiais espaciais e temporais portugueses, en K. Oliveira, H. Cunha e Souza, J. Soledade (Eds.), Do português arcaico ao portugês brasileiro: outras historias, Salvador: EDUFSA, pp. 77-99. 
Costa, S. B. B. (2012). Adverbiais espaciais e temporais portugueses: trajetos léxico-semânticos, en T. Lobo (Ed.), Rosae: linguística histórica, história das linguas e outras históricas, Salvador: EDUFBA, pp. 417-440.

Corpas Pastor, G. (1996). Manual de fraseología española. Madrid: Gredos.

Cunha, C. y L. Cintra (1984). Nova Gramática do Português Contemporâneo. Lisboa: João Sá da Costa.

Echenique Elizondo, M. ${ }^{a}$ T. (2003). Pautas para el estudio histórico de las unidades fraseológicas, en J. L. Girón, S. Iglesias, F. Herrero y A. Narvona (Eds.), Estudios ofrecidos al Profesor José Jesús De Bustos Tovar. Madrid: Editorial Complutense, pp. 545-560.

Echenique Elizondo, M. ${ }^{\mathrm{a}}$ T. (2010). Las unidades fraseológicas en la historia del español, en P. Civil y F. Crémux (Coords.), Nuevos caminos del hispanismo. Actas del XVI Congreso de la Asociación Internacional de Hispanistas. Madrid: Iberoamericana, p. 12.

Echenique Elizondo, M. ${ }^{a}$ T. (2011). Fraseología vasco-románica. Acotaciones para su estudio, en Oihenart: cuadernos de lengua y literatura, 26, pp. 145-162.

Echenique Elizondo, M. ${ }^{a}$ T., Martínez Alcalde, M. ${ }^{a}$ J., Sánchez Méndez, J. P. y F. Pla Colomer (2016). Fraseología española: diacronía y codificación. Madrid: Anejos de la Revista de Filología Española. https://doi.org/10.5209/CLAC.56326

Echenique Elizondo, M. ${ }^{a}$ T., Martínez Alcalde, M. J. y F. Pla Colomer (2017). La fraseología a través de la historia de la lengua española y su historiografía. Valencia: Tirant Humanidades.

Echenique Elizondo, M. a T., Schrott, A. y F. Pla Colomer (2018). Cómo se "bacen” las unidades fraseológicas: continuidad y renovación en la diacronía del espacio castellano. Frankfurt am Main: Peter Lang. https://doi.org/10.3726/b14461

Espinosa Elorza, R. M. (2010). Procesos de formación y cambio en las llamadas 'palabras gramaticales'. San Millán de la Cogolla: Cilengua.

Espinosa Elorza, R. M. (2012). Cambios sintácticos en el siglo XIX, en J. L. Ramírez Luengo (Ed.), Por sendas ignoradas. Estudios sobre el español en el siglo XIX. Lugo: Axac, pp. 61-74.

Fagard, B. (2009). Prépositions et locutions prépositionnelles: un sémantisme comparable?, Langages, 173, pp. 95113. https://doi.org/10.3917/lang.173.0095

García-Page Sánchez, M. (1998). "Expresión fija y sinonimia”, en G. Wotjak (Ed.), Estudios de fraseología y fraseografía del español actual. Frankfurt am Main y Madrid: Iberoamericana Vervuert, pp. 83-95. https://doi.org/10.31819/9783865278371-006

García-Page Sánchez, M. (2008). Introducción a la fraseología española. Estudio de las locuciones. Barcelona: Anthropos.

García Valle, A. y A. Ricós Vidal (2017). La expresión de la causa a través de las combinaciones locucionales prepositivas medievales en las crónicas alfonsíes y en sus traducciones al gallego y al portugués, en M. ${ }^{a}$ T. Echenique Elizondo, M. ${ }^{a}$ J. Martínez Alcalde y F. P. Pla Colomer, La fraseología a través de la historia de la lengua española y su historiografía. Valencia: Tirant Humanidades, pp. 87-111. 
García Valle, A. (2018). Para la diacronía de las locuciones prepositivas de finalidad en el ámbito lingüístico peninsular a partir de las crónicas alfonsíes y sus traducciones al gallego y al portugués, en M. ${ }^{a}$ T. Echenique Elizondo, A. Schrott y F. P. Pla Colomer (Coord.), Cómo se hacen las unidades fraseológicas: continuidad y renovación en la diacronía del espacio castellano. Frankfurt am Main: Peter Lang, pp. 187-208.

Gómez Asencio, J. (2003). De las locuciones adverbiales, ¿qué se hizo en la tradición gramatical española? Interlingüistica, 14, pp. 59-76.

Gómez Asencio, J. (2008a). El tratamiento de lo que ahora se llama "locuciones prepositivas" en sesenta y cuatro gramáticas del español (1555-1930) [1], Quaderns de filología. Estudis lingüistics, 13, pp. 39103.

Gómez Asencio, J. (2008b). El tratamiento de lo que ahora se llama "locuciones prepositivas" en sesenta y cuatro gramáticas del español (1555-1930) [2], en M. Maquieira Rodríguez y M. D. Martínez Gavilán (Eds.), Gramma-temas 3: España y Portugal en la tradición gramatical. León: Universidad de León, Centro de Estudios Metodológicos e Interdisciplinares, pp. 75-104.

Griera, A. (1931). Gramàtica històrica del català antic. Barcelona: Instituto Patxot.

Lapesa Melgar, R. (1992 [1981]). Alma y ánima en el Diccionario histórico de la lengua española: su fraseología, R. Lapesa, Léxico e historia. II. Diccionarios. Madrid: Istmo, pp. 79-86.

Machado, N. I. P. (2013). As locuções adverbiais temporais e aspectuais nos séculos XVIII e XIX do português: um estudo da ordem, Lingüistica, 29: 1, pp. 59-80.

Martín Zorraquino, M. ${ }^{a}$ A. (2002). Reflexiones sobre el estudio de los marcadores del discurso desde la perspectiva diacrónica., en M. ${ }^{a}$ T. Echenique Elizondo y J. Sánchez Méndez (coord.), Actas del $V$ Congreso Internacional de Historia de la Lengua Española. Madrid: Gredos, 285-293.

Moll Casanovas, F. (1952). Gramática histórica catalana. Madrid: Gredos.

Montoro del Arco, E. (2006). Teoría fraseológica de las locuciones particulares. Las locuciones prepositivas, conjuntivas y marcadoras en español. Frankfurt am Main: Peter Lang.

Ocampo, F. (2006a). Movement towards discourse is not grammaticalization: The evolution of 'claro' from adjective to discourse particle in spoken Spanish, en N. Sagarra y J. Toribio, Almeida (Ed.), Selected proceedings of the $9^{\text {th }}$ Hispanic Linguistics Symposium. Somerville: Cascadilla Proceedings Project, pp. 308-319

Ocampo, F. (2006b). La evolución de 'bueno' de adjetivo a partícula discursiva. Un proceso de discursivización, Oralia: Análisis del discurso oral, 9, pp. 231-257.

Octavio de Toledo y Huerta, Á. (2016). Los relacionantes locativos en la historia del español. Berlín y Boston: De Gruyter. https://doi.org/10.1515/9783110458510

Ortiz Ciscomani, R. M. (2014). Locuciones adverbiales con 'a' y base lexica en '-as', en C. Company Company (Coord.), Sintaxis histórica de la lengua española, vol. 3, pp. 1117-1192. 
Ortiz Ciscomani, R. M. (2017). From adjective to adverbial modal locutions in Spanish, en M. Hummel y S. Valera (Ed.), Adjective Adverb Interfaces in Romance, pp. 305-327. https://doi.org/10.1075/la.242.12ort

Penadés Martínez, I. (2006). Sinonimia y locuciones, en M. Villayandre Llamazares (Ed.), Actas del V Congreso de Lingüistica General. Madrid: Arco, pp. 2217-2227.

Perera i Parramon, J. (1986). Contribució a l'estudi de les preposicions en el "Tirant lo Blanc" (primera part), en Llengua i Literatura, 1, pp. 51-109.

Perera i Parramon, J. (1987). Contribució a l'estudi de les preposicions en el "Tirant lo Blanc" (segona part), en Llengua i Literatura, 2, pp. 19-66.

Pla Colomer, F. P. (2017). Fundamentos para una fraseometría histórica del español, Rhytmica: revista española de métrica comparada, 15, pp. 87-112. https://doi.org/10.5944/rhythmica.21192

Pla Colomer F. P. y S. Vicente Llavata (2019). Estudio fraseológico-contrastivo de textos castellanos y gallego-portugueses de materia troyana, en M. J. Lacarra y N. Aranda García (Coord.), Literatura medieval hispánica: «Libros, lecturas y reescrituras». San Millán de la Cogolla: Cilengua, pp. 953-970

Pons, S. y L. Ruiz (2001). Los orígenes del conector de todas maneras: fijación formal y pragmática, Revista de Filología Española, 81, pp. 317-351. https://doi.org/10.3989/rfe.2001.v81.i3/4.180

Porcel Bueno, D. (2016a). Los procesos de derivación locucional en el continuum discursivo de la literatura medieval de castigos. Memorabilia. Boletín de literatura sapiencial, 18, pp. 235-250.

Porcel Bueno, D. (2016b). Formas locucionales prepositivas en los libros y colecciones de sentencias castellanas del siglo XIII, en M. ${ }^{a}$ T. Echenique Elizondo, M. ${ }^{a}$ J. Martínez Alcalde y J. P. Sánchez Méndez (Eds.), Fraseología española: diacronía y codificación. Madrid: Anejos de la Revista de Filología Española, pp. 67-83.

Porcel Bueno, D. (2017a). Hacia una nueva categorización de las unidades fraseológicas desde una perspectiva histórica: locuciones prepositivas y formas locucionales prepositivas en el castellano del siglo XIV, E-Spania. Revue interdisciplinaire d'études hispaniques médiévales et modernes, 29, pp. 23-35 https://doi.org/10.4000/e-spania.27657

Porcel Bueno, D. (2017b). Unidades fraseológicas, tradiciones discursivas y géneros textuales en diacronía, en M. ${ }^{a}$ T. Echenique Elizondo, M. ${ }^{a}$ J. Martínez Alcalde y F. P. Pla Colomer (Eds.), La fraseología a través de la historia de la lengua española y su historiografía. Valencia: Tirant Humanidades, pp. 173-194.

Porcel Bueno, D. (2018): Variación lingüística y variación textual en la fraseología castellana: disquisiciones diacrónicas en torno al sistema locucional prepositivo, en M. ${ }^{a}$ T. Echenique Elizondo, A. Schrott y F. P. Pla Colomer (Eds.), Cómo se "bacen” las unidades fraseológicas: continuidad y renovación en la diacronía del espacio castellano. Frankfurt am Main: Peter Lang, pp. 55-70.

Quilis Merín, M. (2008). De Nebrija a Franciosini (1495?-1620): presencia y consolidación de las locuciones adverbiales en la lexicografía histórica del español, en C. Company Company y J. G. Moreno de Alba (Eds.), Actas del VII Congreso Internacional de Historia de la Lengua Española, vol. 1, Madrid: Arco Libro, pp. 1017-1034. 
Ricós Vidal, A. (2006). Las unidades fraseológicas en los textos hispanos y lusos del siglo XVI: el ejemplo de Gil Vicente, en J. L. Girón Alconchel y J. J. de Bustos Tovar (Eds.), Actas del VI Congreso Internacional de Historia de la Lengua española. Madrid: Arco Libros, pp. 2039-2050.

Ricós Vidal, A. (2008). Locuciones adverbiales con preposición a y adjetivo en el español y el portugués del siglo XVI. Estudio histórico, en C. Company Company y J. G. Moreno de Alba (Eds.), Actas del VII Congreso Internacional de Historia de la Lengua Española, vol. 1. Madrid: Arco, pp. 1035-1054.

Ricós Vidal, A. (2011). As locuções adverbiais nos dicionários trilingues seiscentistas portugueses, en $\mathrm{H}$. Rebelo (ed.), Lusofonia tempo de reciprocidades: Actas IX Congresso da Associação Internacional de Lusitanistas, pp. 29-40.

Ricós Vidal, A. (2016). El origen de algunas locuciones prepositivas en gallego y portugués: análisis de las crónicas medievales, en M. ${ }^{a}$ T. Echenique Elizondo, M. J. Martínez Alcalde, J. P. Sánchez Méndez (Eds.), Fraseología española: diacronía y codificación. Madrid: Anejos de la Revista de Filología Española, pp. 237-256.

Rodríguez Molina, J. (2014). Adverbios y locuciones adverbiales de manera, en C. Company Company (Coord.), Sintaxis histórica de la lengua española (Tercera parte: Preposiciones, adverbios y conjunciones. Relaciones interoracionales), vol. 3. Distrito Federal de México: Fondo de Cultura Económica, pp. 733-938.

Rodríguez-Piñero Alcalá, A. I. (2011). La sinonimia y la antonimia en el marco de un diccionario de locuciones, LinRed. Lingüistica en la Red, 9, http://www.linred.es/numero9 articulo 6.html.

Rodríguez-Piñero Alcalá, A. I. (2012). Variación y sinonimia en las locuciones, Revista de Lingüistica y Lenguas Aplicadas, 7, pp. 225-238. https://doi.org/10.4995/rlyla.2012.1138

Ruiz Gurillo, L. (1998). Clasificación no discreta de las unidades fraseológicas, en G. Wotjak (Ed.), Estudios de fraseología y fraseografía del español actual. Madrid y Frankfurt: Iberoamericana Vervuert, pp. 13-37. https://doi.org/10.31819/9783865278371-002

Satorre Grau, F. J. (2008). Las locuciones adverbiales en la lexicografía hispanolatina del Siglo de Oro, en C. Company Company y J. Moreno de Alba (Eds.), Actas del VII Congreso Internacional de Historia de la Lengua Española, vol. 1. Madrid: Arco Libros, pp. 1125-1136.

Skelton, R. B. (1971). La locución adverbial de en balde y la fusión fonética, Boletín de la Real Academia Española, 51, Cuaderno 194, pp. 459-474.

Silva, M. E. O. O. (2007). Fraseografía teórica y práctica. Frankfurt am Main: Peter Lang. https://doi.org/10.3726/978-3-653-01515-7

Ullmann, S. (1987). Semántica. Introducción a la ciencia del significado. Madrid: Aguilar.

Vicente Llavata, S. (2011). Estudio de las locuciones en la obra literaria de Don Iñigo López de Mendoza Marqués de Santillana). Hacia una fraseología histórica del español. València: Universitat de València.

Vilaró i Casalinas, F. (1987). La funció de 'en funció de', Revista de Llengua y Dret, 10, pp. 75-82.

Zuluaga Ospina, A. (1980). Introducción al estudio de las expresiones fijas. Tübingen: Max Hueber Verla. 